\title{
Effects of Perceived Health Condition, Gerotranscendence, and Wisdom on Successful Aging of Elders
}

\author{
Hee Kyung Kim \\ Professor, Department of Nursing, Kongju National University, Republic of Korea
}

\begin{abstract}
Background/Objectives: The purpose of this study was to analyse the effect that perceived health condition, gerotranscendence, and wisdom have on successful aging in elders. Methods/Statistical analysis: This study is a descriptive survey design using a convenience sampling. The subjects of this study were 94 elders between 65 years old or above. The data were analyzed using descriptive statistics, t-test, ANOVA, Pearson's correlation coefficient and multiple regression using the SPSS Win 23.0 program. Findings: Successful aging of subjects had positive correlation with perceived health condition, gerotranscendence and wisdom. As a result of conducting the stepwise regression analysis, the explanatory power of above 2 variables was appeared to be $57.8 \%$ including wisdom $(\beta=.713, p<.001)$ and monthly household income $(\beta=.153, p=.032)$.

Improvements/Applications: As a plan to achieve the successful aging of the elders through the results of this study, the government and local governments need to develop a nursing arbitration program for elders to have wise lives in their daily lives and to make efforts to institutionalize the customized job creation considering the ages and conditions of the elders so that they can raise monthly household incomes.
\end{abstract}

Keywords: Elderly, Successful aging, Perceived health condition, Gerotranscendence, Wisdom

\section{Introduction}

According to the extension of the old age along with the growing number of elders, The problems of elders appear in various forms, such as physical change, economic instability, loss of social role, and psychological maladjustment, raising interests in solving these problems. Many elders evaluate that they lived a life without regret when looking back on their own in their old age and hope that they look forward to providing hope and consideration even in the present lives. The life of these elders can be called successful aging. Considering the meaning from various scholars, successful aging means living a psychologically comfortable and happy life by being in good physical health, maintaining a high level of cognitive abilities, being economically stable, exchanging positive interactions with family and people around, and actively

\section{Corresponding Author :}

Hee Kyung Kim,

Professor, Dept. of Nursing, Kongju National

University, E-Mail: hkkim@kongju.ac.kr engaging in social activities ${ }^{[1]}$. Therefore, health care professionals, including nurses, should provide physical, mental, and social care to ensure successful aging for the rest of elders' lives.

For this nursing intervention, it is necessary to preferentially clarify the variables related to successful aging. Based on an analysis of previous studies, the variables of the perceived health condition, gerotranscendence, and wisdom can be considered as mainly related to the physical, psychological, social, and cognitive factors of the elders. First of all, the physical health of the elders aged 65 or older generally has one or more physical illnesses, but the subjective way they judge by themselves is more relevant to the daily lives of elders at the level of physical function than the medical objective way, and it is more appropriate to measure successful aging measuring the health conditions that the elders themselves perceive subjectively ${ }^{[2]}$, so this study includes the health conditions that the elders perceive subjectively. On the psychological side, there is also a phenomenon in which the elders try to overcome their physical and mental abilities and 
realities that degenerate in the latter half of their old ages and develop into a new dimension beyond time and space. Elders who have reached this gerotranscendence recognize that aging is part of the process of normal human growth and development and naturally accepts changes in physical, psychological, and social aging ${ }^{[3]}$. According to Yang ${ }^{[4]}$ 's study with the subjects of 185 elders, the most influencing variable for successful aging was self-transcendence, and the higher the degree of self-transcendence, the higher the degree of successful aging, so it can be said that gerotranscendence is related to successful aging.

In addition, as wisdom is a mature mental activity that solves the various problems of life through the balanced integration of cognitive, emotional, mental, moral, and relational factors ${ }^{[5]}$, wisdom means cognitively experienced eye, high insight, excellent judgment, and harmonizes with the balanced integration of the personal inner self. Therefore, the wisdom of the elders can be inferred that it plays an important role in a successful life. The previous study of elders in North Jeolla Province also showed that the wisdom of life has a mediated effect on successful aging ${ }^{[6]}$.

Therefore, in this study, I would like to syntagmatically utilize the variables of perceived health conditions, gerotranscendence, and wisdom for elders living in the community to identify the relationship with successful aging, and grasp the effect of these variables on successful aging to use it as basic data for nursing intervention for the successful aging of the elders.

\section{Method}

\section{Subjects}

The subjects of the study are elders aged 65 or older who visit five health clinics located in D city, who have understood the purpose of the study and voluntarily expressed their willingness to participate with the written consent. People who are not diagnosed with dementia or who are with mild dementia, who can communicate and do not have a mental illness. To verify the fitness of the sample size, the $G^{*}$ Power 3.0 program was used and a significance level of .05 , effect size of .15 , verification power of .80 and 5 predictive factors were applied to the regression analysis to acquire the final number of 92 subjects. A total of 94 copies were used in the final analysis.

\section{Instruments}

\subsection{Perceived health condition}

The tool developed by Speak, Cowart \& Peller ${ }^{[7]}$ and used by $\mathrm{Kim}^{[8]}$ was used. With a total of three questions, the higher the score on a five-point scale from 1 "very bad" to 5 "very good," the higher the perception of health conditions. Cronbach's $\alpha=.85$ at the time of the development and .78 in this study.

\subsection{Gerotranscendence}

Nine questions concerning Transcendence, a subarea, of the Successful Aging Inventory-Korean, which was designed by Troutman et al. and whose reliability and validity was verified by $\mathrm{Kim}^{[9]}$ 's translation, were used. It is a four-point Likert scale from 1 "Strongly Disagree" to 4 "Strongly Agree" and the higher the respondents' scores, the higher the degree of gerotranscendence they feel. Cronbach's $\alpha=.71$ in Kim ${ }^{[9]}$ 's study and 70 in this study.

\subsection{Wisdom}

Korean Wisdom Scale (KMWS) developed by $\mathrm{Kim}^{[10]}$ was used. A total of 43 questions consist of four sub-areas. The higher the score, the higher the degree of wisdom, with the five-point scale from 1 "Strongly Disagree" to 5 "Strongly Agree". Cronbach's $\alpha=.93$ of reliability at the time of the development and .97 in this study.

\subsection{Successful aging}

The successful aging tool of Korean elders developed by $\mathrm{Kim}^{[11]}$ was used. This tool consists of 31 questions. The higher the score, the higher the degree of successful aging, on a scale from 1 "Strongly Disagree" to 5 "Strongly Agree". Cronbach's $\alpha=.92$ in Kim ${ }^{[11]}$ 's study and .95 in this study.

\section{Data collection}

The data collection period was from April 20 to May 20, 2020. The researcher explained the purpose and method of the research to the heads of five health clinics located in D city and obtained permission for the same data collections after two meetings with the heads 
of health clinics with the researcher. The heads of health clinics were required to read and respond directly to elders who visited the health clinics. It took about 20 minutes to complete the questionnaire.

\section{Ethical consideration}

The researcher explained in advance that the subject would not have to respond if they were reluctant to reveal personal information. The researcher explained that subjects can stop or withdraw the answering at any time if they do not want to participate in the study. It was approved by the K University's Institutional Review Board for the data collection of this study(KNUIRB-2020-12). During the study period the guidelines on ethical studies were observed.

\section{Data analysis}

Using the SPSS/WIN 23.0 program, the subjects' general characteristics and variables were analyzed for frequency, percentage, mean, and standard deviation. The difference in successful aging according to general characteristics was analyzed using t-test, ANOVA and Scheffé test. 각 The correlation between each variable was Pearson's correlation coeffects, and the influence factors of successful aging were analyzed using stepwise multiple regression.

\section{Result And Discussion}

\section{General characteristics of subjects}

The average age of subjects was 74.81 years old. The elderly aged $70-79$ accounted for $42(44.7 \%)$ of the population. $51(54.3 \%)$ of the subjects said that they do not have religion, and as for the state of marriage, marriage is $63(67.0 \%)$, and majority. $71(75.5 \%)$ were living with more than one family. Most of the subjects $(70,74.5 \%)$ thought that monthly allowance was more than normal degree, and $67(72.3 \%)$ earned less than 1.5 million won per month. 56(59.6\%) of the subjects graduated from elementary school and 51(54.3\%) of the subjects had more than two diseases. 57(60.6\%) answered that they were exercising. As for friendship with friends, most of $86(91.5 \%)$ answered that they are connected[Table 1].

Table 1. General Characteristics and Difference of Successful aging according to Characteristics ( $N=94)$

\begin{tabular}{|c|c|c|c|c|}
\hline \multirow{2}{*}{ Characteristics } & \multirow{2}{*}{$\begin{array}{l}\text { Cate } \\
\text { gories }\end{array}$} & \multirow[b]{2}{*}{ n(\%) } & \multicolumn{2}{|c|}{ Successful aging } \\
\hline & & & $\mathbf{M} \pm \mathbf{S D}$ & $\begin{array}{l}\mathrm{t} / \mathrm{F} \\
(\mathrm{P})\end{array}$ \\
\hline \multirow{3}{*}{$\begin{array}{l}\text { Age } \\
\text { (years) }\end{array}$} & $65-69$ & $25(26.6)$ & $3.76 \pm 0.64$ & $\begin{array}{l}1.90 \\
(.155)\end{array}$ \\
\hline & $70-79$ & $42(44.7)$ & $3.62 \pm 0.53$ & \\
\hline & $80+$ & $27(28.7)$ & $3.43 \pm 0.66$ & \\
\hline \multirow{2}{*}{ Religion } & Yes & $43(45.7)$ & $3.75 \pm 0.56$ & $\begin{array}{l}2.23 \\
(.028)\end{array}$ \\
\hline & No & $51(54.3)$ & $3.47 \pm 0.62$ & \\
\hline \multirow{2}{*}{$\begin{array}{l}\text { Marital } \\
\text { Status }\end{array}$} & Living together & $63(67.0)$ & $3.66 \pm 0.56$ & $\begin{array}{l}1.01 \\
(.316)\end{array}$ \\
\hline & $\begin{array}{l}\text { Separation by death, } \\
\text { divorce, etc }\end{array}$ & $31(33.0)$ & $3.52 \pm 0.68$ & \\
\hline \multirow{2}{*}{ Family living together } & No & $23(24.5)$ & $3.48 \pm 0.67$ & $\begin{array}{l}-1.09 \\
(.277)\end{array}$ \\
\hline & More than one person & $71(75.5)$ & $3.64 \pm 0.58$ & \\
\hline
\end{tabular}


Cont... Table 1. General Characteristics and Difference of Successful aging according to Characteristics $(\mathrm{N}=94)$

\begin{tabular}{|c|c|c|c|c|}
\hline \multirow{2}{*}{$\begin{array}{l}\text { Ideas of the monthly } \\
\text { pocket money }\end{array}$} & Not enough & $24(25.5)$ & $3.40 \pm 0.62$ & $\begin{array}{l}-1.91 \\
(.059)\end{array}$ \\
\hline & Above normal & $70(74.5)$ & $3.67 \pm 0.59$ & \\
\hline \multirow{2}{*}{$\begin{array}{l}\text { Monthly Household } \\
\text { Income }\end{array}$} & Less than 1.51 million won & $67(72.3)$ & $3.49 \pm 0.61$ & $\begin{array}{l}-3.03 \\
(.005)\end{array}$ \\
\hline & More than 1.51 million won & $27(28.7)$ & $3.90 \pm 0.51$ & \\
\hline \multirow{2}{*}{ Academic Background } & $\begin{array}{l}\text { Graduated from elementary } \\
\text { school or below }\end{array}$ & $56(59.6)$ & $3.50 \pm 0.64$ & $\begin{array}{l}-2.10 \\
(.039)\end{array}$ \\
\hline & $\begin{array}{l}\text { Middle school dropout or } \\
\text { higher }\end{array}$ & $38(40.4)$ & $3.76 \pm 0.52$ & \\
\hline \multirow{2}{*}{ The number of diseases } & Less than one & $43(45.7)$ & $3.67 \pm 0.61$ & \begin{tabular}{|l|}
0.83 \\
$(, 409)$ \\
\end{tabular} \\
\hline & Two or more & $51(54.3)$ & $3.55 \pm 0.61$ & \\
\hline \multirow{2}{*}{ Exercise } & Do & $37(39.4)$ & $3.48 \pm 0.69$ & \begin{tabular}{|l|l|}
-1.32 \\
$(.102)$ \\
\end{tabular} \\
\hline & Don't do & $57(60.6)$ & $3.65 \pm 0.53$ & \\
\hline \multirow{2}{*}{$\begin{array}{l}\text { Having a friend } \\
\text { ship }\end{array}$} & Have & $8(8.51)$ & $3.32 \pm 0.61$ & $\begin{array}{l}-1.36 \\
(.176) \\
\end{array}$ \\
\hline & Don't have & $86(91.5)$ & $3.63 \pm 0.61$ & \\
\hline
\end{tabular}

\section{Descriptive statistics of the variables}

The mean of subjects' perceived health condition was $2.96 \pm 0.75,2.60 \pm 0.57$ for gerotranscendence, $3.29 \pm 0.57$ for wisdom, and $3.60 \pm 0.61$ for successful aging[Table 2].

Table 2. Descriptive Statistics of the Variables

\begin{tabular}{|l|l|l|l|}
\hline Variables & M \pm SD & Min & Max \\
\hline Perceived health condition & $2.96 \pm 0.75$ & 1.00 & 5.00 \\
\hline Gerotranscendence & $2.60 \pm 0.57$ & 1.44 & 6.11 \\
\hline Wisdom & $3.29 \pm 0.57$ & 1.93 & 4.53 \\
\hline Successful aging & $3.60 \pm 0.61$ & 1.94 & 4.81 \\
\hline
\end{tabular}

3. Difference of successful aging according to general characteristics

The difference of successful aging according to general characteristics showed significant difference according to religion $(\mathrm{t}=2.23, \mathrm{p}=.028)$, monthly household income $(\mathrm{t}=-3.03, \mathrm{p}=.008)$ and education $(\mathrm{t}=-$ $2.10, p=.039$ ). In other words, elders with religion, elders with income of more than 1.51 million won, and elders 
with the academic background of more than middle school dropouts had a higher level of successful aging awareness[Table 1].

\section{Correlations among the variables}

Successful aging of subjects had positive correlation with perceived health condition $(\mathrm{r}=.30, \mathrm{p}=.003)$, gerotranscendence $(r=.35, p=.001)$ and wisdom $(r=.744$, $\mathrm{p}<.001)$ [Table 3].

Table 3. Correlations among the Variables

\begin{tabular}{|l|l|l|l|}
\hline Variables & $\begin{array}{l}\text { Perceived } \\
\text { health } \\
\text { condition } \\
\mathrm{r}(\mathrm{p})\end{array}$ & $\begin{array}{l}\text { Gerotrans } \\
\text { cendence } \\
\mathrm{r}(\mathrm{p})\end{array}$ & $\begin{array}{l}\text { Wisdom } \\
\mathrm{r}(\mathrm{p})\end{array}$ \\
\hline $\begin{array}{l}\text { Successful } \\
\text { aging }\end{array}$ & $\begin{array}{l}.30 \\
(.003)\end{array}$ & $\begin{array}{l}.35 \\
(.001)\end{array}$ & $\begin{array}{l}.74 \\
(<.001)\end{array}$ \\
\hline
\end{tabular}

\section{Factors affecting successful aging of subjects}

Successful aging was set as a dependent variable for a multiple regression analysis. The self-correlation coefficient of Durbin-Watson was 2.021, and VIF value was 1.046 which is smaller than 10 , indicating that there were no issues of multi-linearity.

The analysis showed that wisdom $(\beta=.718, \mathrm{p}<.001)$, and monthly household income $(\beta=.153, \mathrm{p}=.032)$ (more than 1.51 million won) had a significant effect on successful aging in elders. The regression analysis was statistically significant $(\mathrm{F}=61.61, \mathrm{p}<.001)$, with the combined explanatory power of wisdom, and monthly income being $57.8 \%$. Among them, the most influential variable was wisdom[Table 4].

Table 4. Factors affecting successful aging of subjects

\begin{tabular}{|l|l|l|l|l|l|}
\hline Variables & B & SE & $\boldsymbol{\beta}$ & $\mathbf{t}$ & $\mathbf{p}$ \\
\hline Constant & 1.044 & .245 & & 4.256 & $<.001$ \\
\hline Wisdom & .760 & .075 & .718 & 10.183 & $<.001$ \\
\hline $\begin{array}{l}\text { Monthly household } \\
\text { income(more than 1.51 } \\
\text { million won) }\end{array}$ & .206 & .094 & .153 & 2.183 & .032 \\
\hline $\mathrm{R} 2=.578$, Adj $\mathrm{R} 2=.569, \mathrm{~F}=61.61, \mathrm{p}<.001$ \\
\hline
\end{tabular}

Reference category: monthly household income $=$ Less than 1.51 million won

\section{Discussion}

This study sought to provide basic data on nursing intervention development for the successful aging of the elders by identifying the effects of perceived health conditions, gerotranscendence, and wisdom on the successful aging of the elders.

The perceived health conditions of the elders, gerotranscendence, and wisdom had a positive correlation with successful aging, and the factors affecting the successful aging of the elders were wisdom and household monthly income. It showed that these variables explain 57.8 percent of successful aging.

According to a study ${ }^{[12]}$ of 172 elderly people in rural areas, it showed a positive correlation between perceived health conditions and successful aging, and the factors affecting successful aging are similar to this study. The perceived health condition of elders is the overall health condition, including objective health condition and subjective health care needs, which is the recognition of daily activities and health conditions in their lives. Therefore, recognizing that their health is better than the number of diseases can be an important clue for the health of the elders. Therefore, nurses who are primary health workers should create a health-related local environment and provide professional care for the elders' regular health behaviors. In addition, a study of 185 elderly women ${ }^{[4]}$ found that self-transcendence had a net correlation with successful aging and was the most influential variable in successful aging. And a study of 174 elderly women ${ }^{[13]}$ showed a strong net correlation between self-transcendence and successful aging. In addition, 152 Korean elderly men ${ }^{[14]}$ found that wisdom has a mediating effect in the relationship between selfesteem and successful aging, and also in the study of 513 elderly Koreans living in the community ${ }^{[15]}$, there is a net correlation between wisdom and successful aging and the wisdom was found to be an influencing factor for successful aging, which was consistent with the result of this study. If both men and women have gerotranscendence in their old age, I believe that they will be able to achieve successful aging by showing a positive attitude toward life because they can maintain the meaning and purpose of life, be interested in 
contributing to the next generation, and control and manage themselves ${ }^{[16]}$ out of everyday life. Moreover, elders who have reached the gerotranscendence tend to accept physical, psychological, and social aging naturally, thinking that aging is part of the process of human growth and development ${ }^{[3]}$. Also, a wise person tends to accept the positive and negative aspects of reality and be satisfied with his or her own life, so he or she can lead a successful life in old age. Yang ${ }^{[4]}$ 's study is similar to this study because the amount of monthly spending money for the elders was a factor affecting successful aging. As the economic condition is a major variable in managing the lives of the elders, the support is needed to ensure that the elders do not suffer from economic problems. I hope that there will be more opportunities for elders to get financial helps through works, considering their own levels of health. Economic welfares such as job creation through the invigoration of exchanges with social enterprises and local businesses are required.

\section{Conclusion}

According to the above results, As wisdom enables integrated and overall access to life's challenges and problems, they can achieve successful aging if they support their wise lives. And the economic aspect has also proved to be a major factor of successful aging. Therefore, nurses need to interact with agencies concerned to provide policy-level and institutional support by developing and applying nursing intervention considering these factors.

This study is meaningful in that it is an integrated approach that considered physical, mental, and cognitive variables for the successful aging of the elders.

Ethical Clearance: Not required

\section{Source of Funding: Nil}

\section{Conflict of Interest: Nil}

\section{References}

1. Jeon EH. Development and validation of successful aging scale for elderly women [doctoral dissertation], Kyungsung University, Busan; 2011.

2. Kim YS. A study on the health status and Health promoting behavior in the aged longevity area and urban area in Che-ju [master's thesis], Seoul National University, Seoul; 2000.

3. Tornstam L. Gerotranscendence: A developmental theory of positive aging. Springer Publishing Company, 2005.

4. Yang BAS. A study on the self-transcendence, social support and successful aging of female elderly [master's thesis], Kongju National University, Gongju; 2013.

5. Choi SH. The study of the wisdom of seniorswith relation of self-esteem, satisfaction of life, and psychological well-being, cognitive function as the central figure [doctoral dissertation]. Hoseo University, Cheonan; 2014.

6. Park YC. A Study on the factors influencing successful aging of the elderly [doctoral dissertation], Wonkwang University, Iksan; 2015.

7. Speake DL, Cowart ME, Pellet K. Health perceptions and lifestyles of the elderly. Research of Nursing Health. 1989; 12(2): 93-100.

8. Kim, SH. Factors affecting the perceived health status in the bereaved old people [master's thesis], Chung-Ang University, Seoul; 2010.

9. Kim, EJ. Accessing factor structure and construct validity of the successful aging inventory. Journal of Korean Academy of Nurse, 2013; 43(4): 568578.

10. Kim, MH. Development and validation of a wisdom scale for Korean senior citizens. [doctoral dissertation], Kyungsung University, Pusan, 2014.

11. Kim, DB. The study on the development of the Korean elderly's successful aging scale. Korean Academy of Social Welfare, 2008; 60(1): 211-231.

12. Jung HY, Jeong HM. The effects of perceived health status and society support and health promotion behaviors on successful aging of the elderly in rural area. Journal of the Korean Data Analysis Society, 2016; 18(4): 2167-2181.

13. Kim EJ, Kim YH. Predictors of Successful Aging in Korean Older Women Based on Successful Aging Theory (SAT). Korean J Women Health Nurs. 2011; 17(4): 378-387.

14. Kim HK. Mediating effects of social networks and wisdom on the relationship between self-esteem and successful aging among elderly Korean men. International Journal of Applied Engineering Research. 2014; 9(20): 7919-7936. 
15. Sung KW. Relation of successful aging and wisdom in Korean older adults. J Korean Geronto Nurs. 2011; 13(1): 48-57.
16. Kim HK. Gender difference of the influencing factors on successful aging among rural communitydwelling Korean elders. Journal of the Korean Gerontological Society. 2012; 32(3): 819-834. 